\title{
Chromatin assembly factor I contributes to the maintenance, but not the re-establishment, of silencing at the yeast silent mating loci
}

\author{
Shinichiro Enomoto and Judith Berman ${ }^{1}$ \\ Department of Plant Biology and Plant Molecular Genetics Institute, University of Minnesota, \\ St. Paul, Minnesota 55108 USA
}

CA C 1/RLF2 encodes the largest subunit of chromatin assembly factor I (CAF-I), a complex that assembles newly synthesized histones onto recently replicated DNA in vitro. In vivo, cac1/rIf2 mutants are defective in telomeric silencing and mislocalize Raplp, a telomere-binding protein. Here, we report that in cells lacking CAF-I the silent mating loci are derepressed partially. MAT a cacl cells exhibit an unusual response to $\alpha$-factor: They arrest and form mating projections (shmoos) initially, but are unable to sustain the arrest state, giving rise to clusters of shmooing cells. cac1 MAT a H MLa H M Ra strains do not form these shmoo clusters, indicating that derepression of HML $\alpha$ causes the shmoo cluster phenotype in cac1 cells. When SIR3 is reintroduced into sir1 sir3 cells, H ML remains derepressed indicating that SIR 1 is required for the re-establishment of silencing at $H M L$. In contrast, when SIR3 is reintroduced into cac1 sir3 cells, silencing is restored to HML, indicating that CAF-I is not required for the re-establishment of silencing. Loss of the other CAF-I subunits (Cac2p and Cac3p/Msi 1p) also results in the shmoo cluster phenotype, implying that loss of CAF-I activity gives rise to this unstable repression of $\mathrm{HML}$. Strains carrying certain mutations in the amino terminus of histone H4 and strains with limiting amounts of Sir2p or Sir3p also form shmoo clusters, implying that the shmoo cluster phenotype is indicative of defects in maintenance of the structural integrity of silent chromatin. MA T a cac ${ }^{-}$sirl double mutants have a synergistic mating defect, suggesting that the two silencing mechanisms, establishment and maintenance, function cooperatively. We propose a model to explain the distinctions between the establishment and the maintenance of silent chromatin.

[Key Words: Silencing; chromatin; Sir proteins; histone acetylation; Rap1 localization factors]

Received August 8, 1997; revised version accepted N ovember 17, 1997.

In differentiated cells, two identical genomic sequences can sometimes be found in two distinct states of expression. For example, in femal e mammals, one of the two $X$ chromosomes is inactivated, whereas the other remains fully active (Latham 1996). Similarly, chromosomal imprinting ensures that a specific locus, when inherited from one parent, is completely inactive, whereas the same locus inherited from the other parent is completely active (Ferguson-Smith 1996). The imprinted state of the locus is inherited through many mitotic divisions and is generally reset only during meiosis. Inappropriate genomic imprinting can cause serious developmental defects, and several human genetic disorders are caused by mutations affecting imprinted genes (Hall 1990; Lalande 1996). Although the molecular mechanisms by which $X$ inactivation and genomic imprinting are initiated and maintained are not well understood, the inactive $X$ chro-

${ }^{1}$ Corresponding author.

E-MAIL berma003@tc.umn.edu; FAX (612) 625-1738 mosome is in a highly condensed heterochromatic state and a similar chromatin state may occur at silenced, imprinted loci (John and Surani 1996).

One of the best studied examples of silencing occurs at the HM loci in the budding yeast Saccharomyces cerevisiae. S. cerevisiae has three mating type loci. Mating type genes expressed from the MAT locus normally determine the yeast mating type, either a or $\alpha$, in haploid cells. Haploid cells normally respond to the mating pheromone of the opposite mating type by arresting in late $\mathrm{G}_{1}$ and forming mating projections (shmoos). In addition, wild-type strains have functional but transcriptionally repressed mating information at the $\mathrm{HM}$ loci, $\mathrm{HML}$ and HMR. If the HM loci become derepressed in haploid cells, both $\mathbf{a}$ and $\alpha$ mating information is expressed and the cells do not arrest growth or form mating projections in response to mating pheromones. Thus, by monitoring the pheromone response of hapl oid cells one can infer the expression state of the HM loci.

The silent state of the HM loci is attributable to a 
special ized form of chromatin that is the yeast version of metazoan heterochromatin (Grunstein 1995; Braunstein et al. 1996). Genes within the HM Ioci are inaccessible to DNA modification enzymes, RNA polymerases II and III, and excision repair enzymes (for review, see Fox and Rine 1996). The acetylation state of histones $\mathrm{H} 3$ and $\mathrm{H} 4$ in the nucleosomes of silent chromatin is different from that of bulk chromatin or of the active MAT Iocus; at the $\mathrm{HM}$ loci, histone $\mathrm{H} 4$ is hypoacetylated except on lysine12 (Braunstein et al. 1996). This is similar to the acetylation pattern conferred on newly synthesized histone $\mathrm{H} 4$ by the cytoplasmic histone acetyltransferase Hatlp (Kleff et al. 1995; Parthun et al. 1996). A number of mutations in acetylated lysines in the amino termini of histones $\mathrm{H} 3$ and $\mathrm{H} 4$ weaken silencing at the $\mathrm{HM}$ loci or at telomeres (for review, see Grunstein 1995). Thus, histone acetylation may play an important role in the inheritance of chromatin expression states.

The Sir complex proteins (composed of Sir2p, Sir3p, and Sir4p and not including Sirlp) are structural components of yeast heterochromatin that associate with histones (Hecht et al. 1996; Strahl-Bolsinger et al. 1997). Loss of any one of these Sir complex proteins abrogates silencing completely (Rine and Herskowitz 1987). Sir3p and Sir4p interact with one another genetically (Ivy et al . 1986; Marshall et al. 1987) and in two-hybrid screens (Moretti et al. 1994), and all three Sir complex proteins can be isol ated in compl exes with each other ( $M$ oazed et al. 1997; Strahl-Bolsinger et al. 1997). Histones H3 and H4 coprecipitate with Sir3p (Hecht et al . 1996), and mutations in the amino termini of either $\mathrm{H} 3$ or $\mathrm{H} 4$ that affect silencing in vivo also affect the interaction of $\mathrm{H} 3$ and $\mathrm{H} 4$ with the Sir complex in vitro (Hecht et al. 1995).

The concentration of Sir complex proteins is critical for silencing. Changes in the stoichiometry of Sir complex proteins al ters silencing (Ivy et al. 1986; M arshall et al. 1987; Sussel et al. 1993). The Sir complex proteins localize to a number of perinuclear foci that are often associated with silent tel omeric DN A (Gotta et al . 1996). These foci are thought to reflect subnuclear domains of high Sir complex concentration in which silent chromatin is local ized (Gotta et al. 1996, 1997). TheHM loci and telomeres compete for Sir proteins, and the proximity of the HM Ioci to telomeres contributes to HM silencing (Buck and Shore 1995; Maillet et al. 1996).

The DNA sequences at the HM loci differ from the sequences at the MAT locus in that each HM locus is flanked by two silencers, $E$ and I. Each E or I silencer contains an autonomously replicating (ARS) consensus sequence that is bound by the origin recognition complex (ORC) (Bell et al. 1993). In addition, each silencer contains a binding site for the ARS-binding factor 1 (Abf1p) or a binding site for the repressor/activator protein 1 (Raplp). The E and I silencers, as well as the individual binding sites and the factors that bind them directly, have redundant functions. In most situations, one silencer is sufficient to silence an $\mathrm{HM}$ locus and any two of the three individual sites within a silencer are sufficient for HM silencing (Brand et al. 1987; M ahoney and Broach 1989; McN ally and Rine 1991). Specific muta- tions in the sites (or in the factors that bind them) reduce the redundancy of HMR silencing and can reveal the roles of silencing factors such as Raplp (Sussel and Shore 1991), ORC (Bell et al. 1993; Micklem et al. 1993; Loo et al. 1995a), and Abf1p (Loo et al. 1995b; Fox et al. 1997).

The study of situations in which silencing is weakened, but not abrogated, has provided important insights into the mechanisms by which silencing occurs. sirl mutants exhibit epigenetic silencing of HML. In a subset of the sirl cells, HML is fully repressed and the repressed state is inherited in most of their progeny; in the remaining sirl cells, HML is fully derepressed and the dere pressed state is inherited (Pillus and Rine 1989). Sirlp interacts physically with both Orclp and with Sir4p (Triolo and Sternglanz 1996). Sirlp, when tethered to the $\mathrm{HML}$ locus in the absence of a silencer, is sufficient to direct silencing (Chien et al . 1993). Deletion of the ORCbinding site also causes defects in the establishment of silencing, which lead to derepression of the HM loci in a subset of the mutant cells (M ahoney et al . 1991; Sussel et al. 1993). Thus, Sirlp contributes to the establi shment of silencing in wild-type cells by interacting with ORC and recruiting structural components of silent chromatin, such as Sir4p, to the silent loci.

Pillus and Rine (1989) proposed that there are two steps in HM silencing: (1) maintenance of the current state of the silent chromatin, and (2) re-establishment of the repressed state when HML becomes derepressed. Although deletion of SIR 1 and mutation of single sites within the HM Ioci cause defects in the re-establishment of silencing, they do not affect the ability to inherit the repressed chromatin state (Pillus and Rine 1989; Mahoney et al. 1991). Derepression of HMR (by inactivation of a temperature-sensitive Sir3 protein) can be restored only after passage through $\mathrm{S}$ phase (Miller and N asmyth 1984), indicating that the re-establishment of silencing requires passage through $\mathrm{S}$ phase. Conversely, Holmes and Broach (1996) demonstrated that if the cis-silencer is excised from the chromosome, the repressed state of the chromatin can be maintained during $\alpha$-factor arrest, but cannot be inherited efficiently. Taken together, these studies indicate that the establishment, maintenance, and inheritance of silencing all contribute to the formation of fully silenced HM loci.

Mammalian chromatin assembly factor I (CAF-I) was identified by its ability to assembl ehistones into nucleosomes in a DN A replication-dependent manner in vitro (Stillman 1986). CAF-I assembles preferentially histones $\mathrm{H} 3$ and $\mathrm{H} 4$ with the acetylation pattern of newly synthesized cytopl asmic histones (Smith and Stillman 1991; Kaufman et al. 1995; Verreault et al. 1996). S. cerevisiae CAF-I is encoded by CAC1, CAC2, and CAC 3 (Kaufman et al . 1997). CAC1, the largest subunit of CAF-I, is identical to RLF2, a gene that we identified in a screen for mutants defective in telomere-related functions (Enomoto et al. 1994, 1997), and CAC3 is identical to MSI 1, a gene identified in high-copy suppressor screens (Ruggieri et al. 1989; Hubbard et al. 1992). All three cac mutant strains display similar phenotypes; cells grow well but are defective in telomeric silencing, the segregation 
of TEL +CEN plasmids, and Raplp localization (Enomoto et al. 1997; Kaufman et al. 1997). Similar phenotypes have been observed in strains carrying mutations in either SIR2, SIR3, or SIR4, in strains carrying mutant alleles of histones $\mathrm{H} 3$ and $\mathrm{H} 4$, and in strains carrying rap1 ${ }^{\text {s }}$ mutations (Enomoto et al. 1994). Because many of these genes are involved in $\mathrm{HM}$ silencing, as well as telomeric silencing, we examined the role of CAF-I in HM silencing.

In this paper we show that CAF-I contributes to the maintenance, but not the re-establishment, of silencing at the HM Ioci. In $\mathrm{cac}^{-}$mutants, we observed a transient Ioss of $\alpha$-factor response, at the individual cell level. Cells form mating projections and divide slowly on $\alpha$ factor, forming clusters of shmooing cells. The formation of shmoo clusters requires $\alpha$-mating information at $H M L$, indicating that this $\alpha$-factor response reflects a defect in the maintenance of HML silencing. We have investigated the relationship between the maintenance and the re-establishment of silencing at HML by analyzing the roles of CAF-I, histones, Sir complex proteins, and Sirlp using $\alpha$-factor confrontation assays.

\section{Results}

cac1 mutations affect HML silencing

$\mathrm{M}$ any of the factors that contribute to telomere position effect also contribute to silencing at the two HM loci $\mathrm{HML}$ and HMR. Although cac1/rlf2 mutants are defective in the repression of telomere adjacent genes, quantitative mating assays did not detect a mating defect in cac $^{-}$strains (Enomoto et al. 1997; Kaufman et al. 1997). We tested HML repression in cacl cells using an $\alpha$-factor response assay that is more sensitive to derepression of $\mathrm{HML} \alpha$ than are quantitative mating assays. Exponentially growing MATa cells were resuspended in liquid medium containing $\alpha$-factor and the proportion of dividing cells (cells with one or more growing buds) and the proportion of arrested cells (unbudded cells with or without mating projections) was determined. Three hours after the addition of $\alpha$-factor, $1 \%$ of the wild-type cells were dividing, whereas $10-20 \%$ of the cells in cacl strains (cac1- $\Delta 1$ and cacl- 1 ) were dividing. This difference between wild-type and cacl cells suggested that either HML is slightly derepressed in all cacl cells or that $\mathrm{HML}$ is derepressed in a population of the cac 1 cells. For comparison, in an isogenic MATasirl strain, $32 \%$ of the cells were dividing in $\alpha$-factor.

CAC1, together with the ORC-binding site, contributes to silencing at HMR

To measure the role of CACl at HMR, we used an HMR::TRP1 construct in which the al and a2 genes are replaced by the TRP1 gene (Hardy et al. 1992). A ssays that measure expression of HMR::TRP1 are more sensitive to low levels of HMR derepression than are mating assays. We constructed a series of isogenic strains carrying the cacl- $\Delta 1$ allele and either HMR::TRP1 (including the intact silencer) or derivatives missing binding sites for either ORC, Abf1p, or Raplp. We compared the ability of these strains to grow on medium lacking tryptophan with the growth of isogenic CAC 1 strains (Fig. 1). Consistent with published results (e.g., Sussel and Shore 1991), only the hmr::TRP1 strain missing the Raplp site grew on medium lacking tryptophan (Fig. 1). In the cacl series of strains, $\operatorname{Trp}^{+}$col onies al so appeared in the strain lacking the ORC site (Fig. 1), suggesting that CAC 1 contributes to silencing at HMR. In addition, this result suggests that $\mathrm{CACl}$ and the ORC-binding site in HMR E are necessary together for HMR silencing.

Interestingly, on medium lacking tryptophan, colonies of cacl hmr::TRP1 strains lacking the ORC site are smaller than colonies formed by either sir4 HMR::TRP1 (data not shown) or sir1 HMR::TRP1 mutants (Fig. 1). sir4 strains are derepressed completely at the HM loci, whereas sirl strains include two populations of cells, those that are repressed and those that are derepressed (Pillus and Rine 1989). Like sirl mutants, strains carrying the rap1-12 mutation (which also causes derepression of hmr::TRP1 in strains lacking the ORC site) give rise to a population of cells that grows without tryptophan and each of these forms a colony that is Iarger than the cacl colonies (Fig. 1). Because on complete medium colonies of cacl hmr:TRP1 strains lacking the ORC site are similar in size to colonies of isogenic wild-type, sirl,

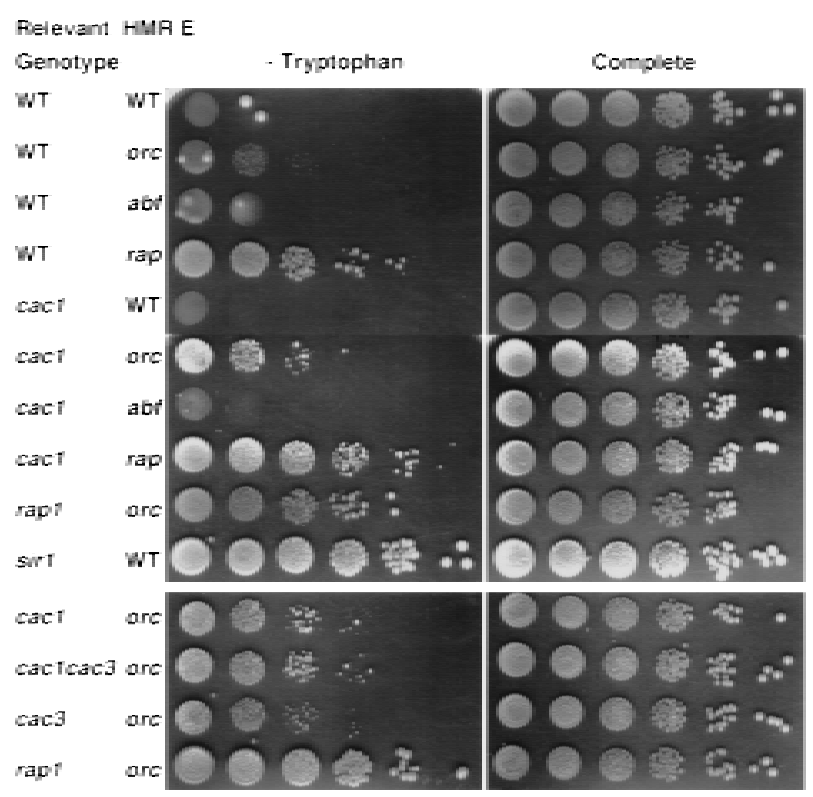

Figure 1. CAF-I contributes to the repression of HMR. Cells with the indicated genotype at the CAC 1, CAC3, RAP1, or SIR1 locus and deleted for the listed sites within HMR E::TRP1 were plated in 10-fold serial dilutions onto medium lacking tryptophan (left) or complete medium (right). Colonies were photographed after 2 days at $30^{\circ} \mathrm{C}$. (Top) Strains used: WT WT, YJB959; WT orc YJB955; WT abf1, YJB1143; WT rap1, YJB1104; cac1 WT, YJB1960; cac1 orc YJB958; cac1 abf1, YJB1139; cac1 rap1, YJB1101; rap1-12 orc, YJB1638; and sir1 WT, YJB2006. (Bottom) Strains used in a separate experiment photographed after 3 days at $30^{\circ} \mathrm{C}$ were: cac1 orc, YJB958; cac3 orc, YJB2011; cac1 cac3 orc, YJB2009; and rap1-12 orc, YJB1638. 
or rap1-12 strains (Fig. 1), the "minicol ony" phenotype observed for cacl cells on medium lacking tryptophan is related specifically to expression of the TRP1 allele in the hmr locus. Because we do not observea population of large T rp ${ }^{+}$colonies in these strains, this observation al so implies that, in contrast to sirl mutants, either none of the cacl cells are derepressed completely when hmr::TRP1 is missing the ORC site, or derepressed cells and their descendants do not remain derepressed as long as sir1 mutant cells.

cacl cells exhibit an unusual budding shmoo response to $\alpha$-factor

MATa cells expressing only a mating information form mating projections, termed shmoos, and arrest in the $\mathrm{G}_{1}$ stage of the cell cycle in response to $\alpha$-factor. However, $\alpha$-factor does not affect the growth and division of cells expressing both a and $\alpha$ mating type genes. To understand the $\alpha$-factor response of cacl strains, we assayed the response of individual MATacacl cells to prolonged $\alpha$-factor treatment on solid medium. After $18 \mathrm{hr}$ at $23^{\circ} \mathrm{C}$, $94 \%$ of the wild-type cells arrested as shmoos in response to the $\alpha$-factor treatment (Fig. 2A). In sirl strains, two populations of cells were observed; $\sim 60 \%$ of the cells arrested as shmoos, and $\sim 40 \%$ of the cells divided actively and formed colonies of round yeast cells (Fig. 2A). The cacl strains exhibited an entirely different response to $\alpha$-factor (Fig. 2). After $18 \mathrm{hr}$, the vast majority of the cacl cells $(85 \%)$ had formed clusters of cells with multi ple shmoo-like projections extending in different directions (Fig. 2A). We have observed similar clusters of shmooing cells in cacl strains in a number of genetic backgrounds (data not shown). In all cases, the vast majority of cacl cells formed these unusual shmoo clusters on $\alpha$-factor at a time that wild-type cel ls were arrested as individual shmoo cells. Individual mating projections contained a nucleus (as determined by DAPI staining) and eventually could be separated by micromani pulation (data not shown), indicating that the mating projections are buds that give rise to individual cells. Eventually ( 12 hr later than cacl cells) wild-type cells formed similar clusters of shmoo cells. After longer periods of time, small colonies of shmooing cacl cells are evident. The presence of shmoos at the colony edges indicated that the dividing cells in the colony were not resistant to $\alpha$-factor. Furthermore, it demonstrated that the $\alpha$-factor in the medium was still active.

To analyze the dynamics of shmoo cluster formation in cacl cells, we observed cells after different times on $\alpha$-factor (Fig. 2B) and followed individual cells by timelapse microscopy (Fig. 2B, bottom row). Virtually all MATacacl cells responded with an initial period of cell cycle arrest. Within the first 3-5 hr on $\alpha$-factor at $23^{\circ} \mathrm{C}$ they formed mating projections at a time when $\alpha$-factorresistant sirl cells were dividing. However, after 8-9 hr of arrest, virtually all of the cacl cells formed a second shmoo-like projection. This second projection continued to grow and a third projection, often projecting perpendicular to the surface of the medium, appeared on most cells by $12 \mathrm{hr}$. At $16 \mathrm{hr}$, a fourth projection appeared on many of the cacl cells, whereas a few of the arrested wild-type shmoos began to form a second projection. $\alpha$ Factor-resistant sirl cells divided approximatel y once every $2 \mathrm{hr}$. In contrast, in cacl cells, new mating projections appeared approximately once every $4 \mathrm{hr}$, and eventually, each mating projection gave rise to an individual cell. This suggests that cacl cells arrested in response to $\alpha$-factor, but eventually resume and complete a cell cycle. We term the groups of cells with multiple mating projections shmoo clusters and the individual cells that arise from each mating projection budding shmoos.

The budding shmoo phenotype occurs in virtually all cacl cells, indicating that, unlike sirl cells, cacl cells do not exist in two distinct epigenetic states. Rather, our observations suggest that cacl cells are all in a similar state that responds to $\alpha$-factor initially, but cannot sustain the $\alpha$-factor response over time.

cac1 $\alpha$-factor-resistant colonies are attributable to expression of $\alpha$ genes from $\mathrm{HML}$

When MATacells encounter $\alpha$-factor, they must commit to a new devel opmental program by repressing pathways that lead to continued cell division and by activating pathways required for cell cycle arrest and polarized growth toward the $\alpha$-factor source. Later on, the process of recovery or adaptation to $\alpha$-factor stimulation is induced. The most parsimonious explanation for the appearance of shmoo clusters in MATa cacl strains exposed to $\alpha$-factor and for the formation of small colonies of cacl hmr::TRP1 strains lacking the ORC site on me di um lacking tryptophan, is that silencing of the HM Ioci is weakened in cacl strains. If this is the case, cacl cells lacking $\alpha 1$ or $\alpha 2$ genes should remain arrested on $\alpha$-factor. However, an alternative possibility is that the loss of CAF-I activity alters directly the transcriptional efficiency of genes that either control cell division or that affect the adaptation of cells to $\alpha$-factor. If this is the case, cacl cells lacking $\alpha 1$ and $\alpha 2$ genes should form shmoo clusters in response to $\alpha$-factor. To distinguish between these two al ternatives, we anal yzed the $\alpha$-factor response of strain YJB2057 (MATacac1 HMRaHMLa), in which a mating information was substituted for $\alpha$ mating information at HML. YJB2057 did not form a second mating projection; only individual shmoo cells were observed (Fig. 2A). Like wild-type strains, these cells remained arrested for $>18 \mathrm{hr}$. This result indicates that $\mathrm{HML} \alpha$ information is required for the budding shmoo phenotype in MATa cacl strains and implies that the unusual $\alpha$-factor response of MATacacl strains is attributable to weakened repression of HML in cells lacking Caclp. Because the cacl cells continue to shmoo and arrest, our results suggest that in all cacl cells, HML oscillates between the repressed state and the derepressed state.

cacl mutations enhance the mating defect of sirl strains

Pillus and Rine (1989) demonstrated that in sirl strains, 
A

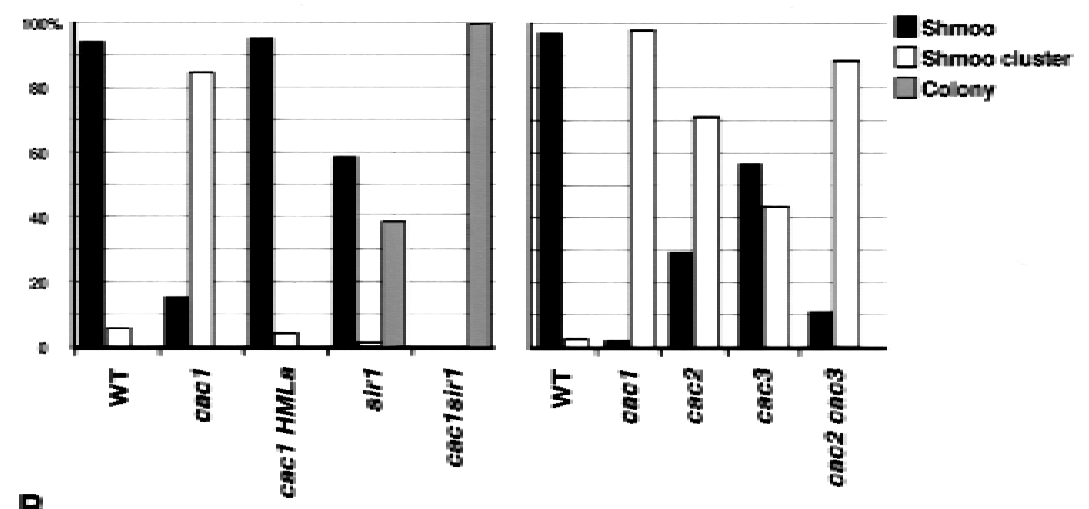

B
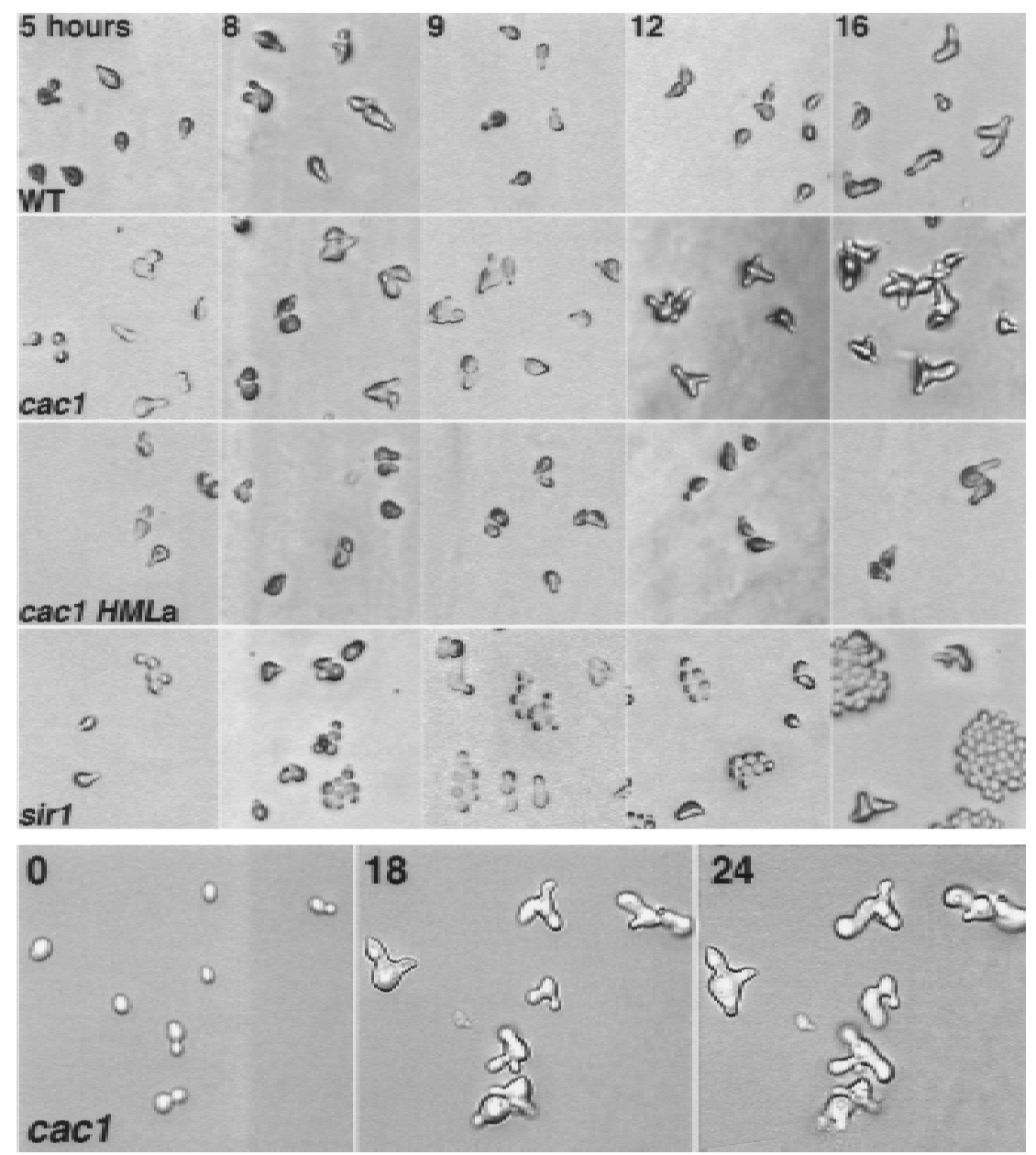

Figure 2. $\alpha$-Factor response of cac strains on solid media. Y east cells were spread onto $\alpha$-factor-YPD plates and maintained at $23^{\circ} \mathrm{C}$. Cells were analyzed at indicated times after exposure to $\alpha$-factor. (A) Analysis of yeast cell populations after $18 \mathrm{hr}$ on $\alpha$-factor. M ore than 100 cells per strain were analyzed. (Shmoo) Individual cells that formed mating projections and remained arrested; (shmoo cluster) individual cells that formed multiple mating projections and eventually divided at least once; (colony) cells that formed colonies of round cells and did not appear to respond to $\alpha$-factor. (Left) Strains used: WT, YJB276; cac1, YJB469; cac1 HMLa, YJB2057; sir1, YJB335; and sir1 cacl, YJB744. (Right) Strains used: WT, YJB195; cac1, YJB1838; cac2, YJB1803; cac3, YJB1581; and cac2 cac3, YJB1865. (Left) $\chi^{2}$ tests indicated that the difference between WT and cacl HMLa strains was not significant, whereas differences between all other pairwise combinations were significant. (Right) All pairwise combinations were significantly different except that the cacl and the cac2 cac3 strains were not significantly different. (B) Analysis of cells over time. (Top four rows) Populations of cells; (bottom row) the same individual cells photographed at indicated times after exposure to $\alpha$-factor. silencing of a derepressed HML locus can be reestablished at a rate of $4 \times 10^{-3}$ changes in state per cell generation. In contrast, if the HML locus is repressed, its repressed state can be maintained in $>90 \%$ of the cells in the absence of Sirlp. We analyzed the response of MATa cacl sirl cells to $\alpha$-factor to determine whether the residual HML repression in cacl single mutants is dependent on Sirlp functions. In other words, when cacl mutants become derepressed after incubation on $\alpha$-factor, is the re-establishment of $\alpha$-factor responsiveness in the next cell cycle dependent on Sirlp function? We reasoned that if residual HML silencing in cacl mutants as independent of Sirlp re-establishment, then the proportion of $\alpha$-factor-resistant cells in the double mutant population should remain similar to the number of $\alpha$ factor-resistant cells in the sirl single mutant population. On the other hand, if $\mathrm{HML}$ repression is relieved transiently in a cacl mutant, and if Sirlp was required 
for re-establishment of the repressed state of $\mathrm{HML}$, then we would expect an increase in the proportion of $\alpha$-factor-resistant colonies in the cacl sirl double mutants. Consistent with the latter expectation, virtually all of the MATa cacl sirl cells were resistant to $\alpha$-factor (Fig. $2 A)$. The proportion of $\alpha$-factor-resistant cells in the double mutant strains was significantly greater than the proportion of $\alpha$-factor-resistant cells in the sirl single mutant strain in two different strain backgrounds (data not shown). In addition, quantitative mating assays confirmed that MATa cacl sirl strains have reduced mating efficiency (Fig. 4, below). It is paradoxical that almost $100 \%$ of cacl sirl cells form "colonies" rather than shmoos or shmoo clusters on $\alpha$-factor, yet the mating efficiency of cacl sirl strains is reduced only 10- to 100fold (depending on the strain background). We think this difference is due to some of the cacl sirl colonies having elongated cells, which we presume to be mating competent. Thus, we conclude that derepression caused by the cacl mutation requires Sirlp to reestabl ish repression in cells where HML becomes derepressed.

CAF-I is not required for the re-establishment of silencing

The re-establishment of silencing at a derepressed HM locus occurs readily in wild-type cells but is a very rare event in sirl cells (Pillus and Rine 1989). We compared the role of cacl and sirl in the re-establishment of silencing by monitoring the state of $\mathrm{HML}$ in sir3 strains in which Sir3p expression was restored by transformation with a centromere plasmid-carrying SIR3 (pSIR3). In all cases, sir3 cells not carrying pSIR3 did not mate (Fig. 3) and did not respond to $\alpha$-factor (data not shown). These strains were then transformed with pSIR3 to provide a single copy of the SIR3 gene expressed from its own promoter. In the otherwise wild-type sir3 pSIR3 strain, mating competence was readily restored and, when exposed to $\alpha$-factor, arrested shmoo cells appeared. As expected, as SIR1 is an important contributor to the re-establishment of HML silencing, the opposite result was seen in the isogenic sirl strain (Fig. 3); sirl sir3 pSIR3 cells did not mate (Fig. 3) and, when exposed to $\alpha$-factor, did not give rise to arrested shmoo cells. Cotransformation with both pSIR3 and a centromere plasmid-carrying SIR1 (pSIR1) in this strain restored mating competence and $\alpha$-factor responsiveness, indicating that it was the lack of
Sirlp that limited the ability of this strain to restore $\mathrm{HML}$ to the repressed state. In contrast, transformation of the cacl sir3 cells with pSIR3 led to the appearance of mating competent cells and these cells arrested as shmoos when exposed to $\alpha$-factor, indicating that HML was restored to the silent state. These results clearly demonstrate that cacl is not required for the re-establishment of silencing when HML has been derepressed.

The HM silencing defect in cacl strains is attributable to the loss of CAF-I function

CAC1 encodes the large subunit of CAF-I, a trimeric complex that includes Caclp/RIf2p, Cac2p, and Cac3p/ M si 1p (Kaufman et al. 1997). To determine whether the HM silencing defect in cacl mutants was attributable to the absence of CAF-I function, we constructed strains carrying mutations in one, two, or all three genes encoding CAF-I subunits and performed quantitative mating assays on both MATa and MAT $\alpha$ mutant strains. Like cacl mutants, the single, double, and triple cac mutants of both mating types were able to mate with wild-type efficiency in quantitative mating assays (Fig. 4). However, all of the single and double cac mutants have measurable MATa mating defects in combination with sirl (Fig. 4). Single and double cac mutants in combination with sirl behaved like the sirl cacl strain; the MATa strains mated with reduced efficiency, whereas the MAT $\alpha$ strain mating was not significantly different from the wild-type, sir1, or cac single mutant strains (Fig. 4).

Like MATa cacl strains, the MATa cac2 and MATa cac3 strains produced shmoo clusters by $18 \mathrm{hr}$ at $23^{\circ} \mathrm{C}$ (see Fig. 2A). Interestingly, cac2 and cac3 mutations caused less severe silencing defects $(61 \%$ and $42 \%$ shmoo clusters, respectively) than did cacl mutants (97\% shmoo clusters), which encodes the largest CAF-I subunit (see Fig. 2A). This may occur because CAC 2 and CAC3 both encode small proteins that include WD40 repeats (Verreault et al. 1996; Kaufman et al. 1997), which may be partially redundant with one another. Consistent with this idea, the silencing defect of cac2 cac3 double mutants ( $89 \%$ shmoo clusters) is not significantly different from that of cacl mutants (see Fig. 2A).

To determine whether loss of any one of the CAF-I components also causes derepression of hmr::TRP1 strains lacking the ORC site, we analyzed the Trp phenotype of strains carrying either cac3 al one or as a double
Figure 3. SIR1 is required, and CACl is not re quired, for the re-establishment of HML silencing. Plasmids pSIR3 (pSE334 or pJR273) and pSIR1 (pJR910) were introduced (indicated by +) into strains carrying sir3 and the other indicated mutations. Two days after transformation, transformants were allowed to mate for $18 \mathrm{hr}$ with a Mat $\alpha$ tester strain (TD1). Diploids were then selected by replica plating onto SDC medium lacking adenine and histidine. Strains used were sir3 sir1, YJB2471; sir3 cac1, YJB2109; sir3, YJB2544; WT, YJB195.

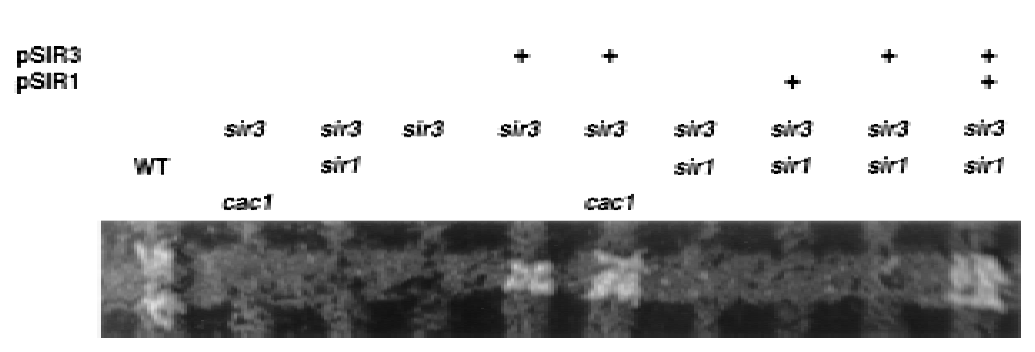




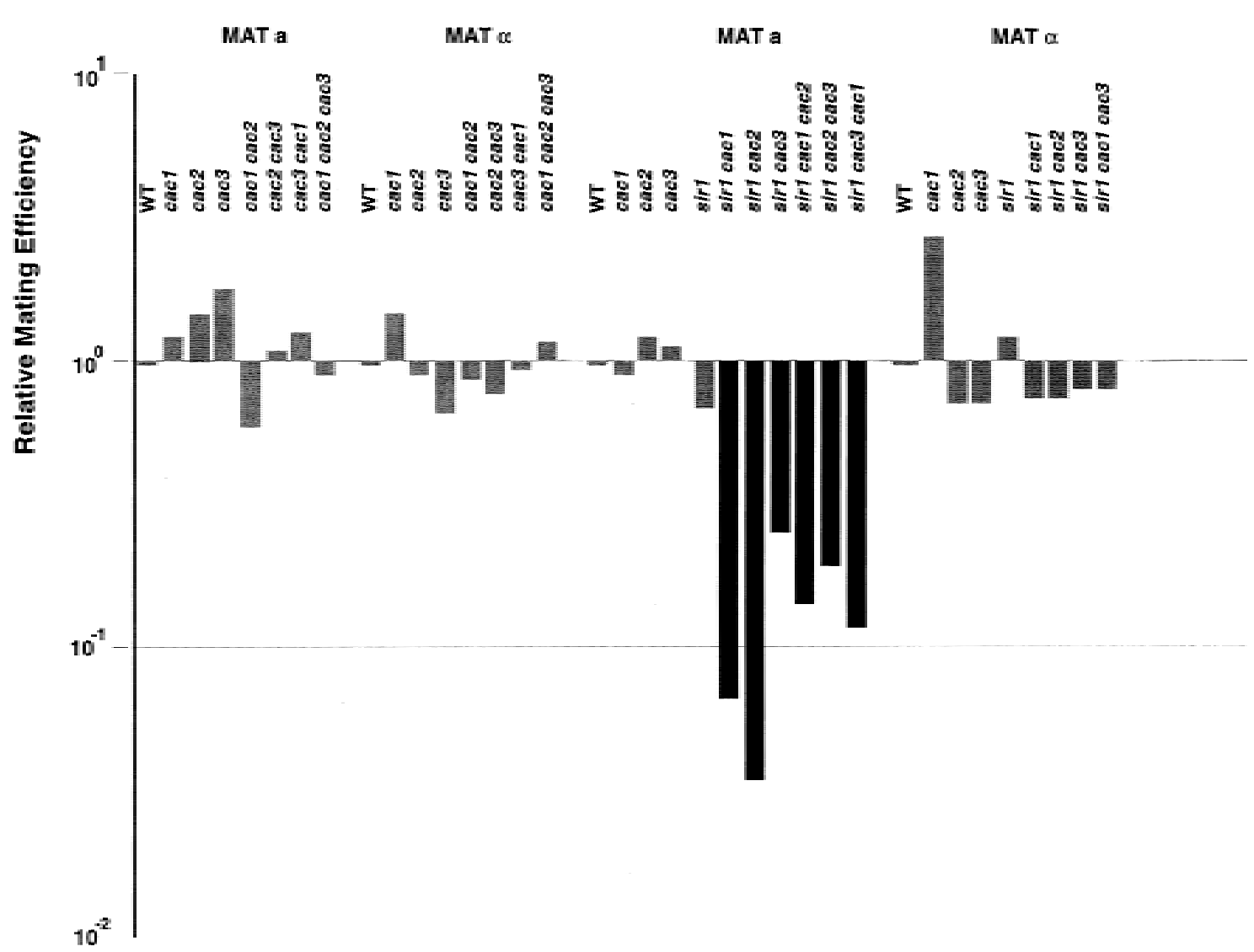

Figure 4. Mutation of CAF-I subunits causes subtle MATa mating defects. At least four individual quantitative mating assays were performed for each strain. The median value of the assays is shown. All values are normalized to the isogenic wild type. Solid bars indi cate that results were statistical ly different from wild type at the $P<0.05$ level. Strains (MATa, MAT $\alpha$ ): WT, YJB195, YJB209; cac1, YJB1838, YJB1578; cac2, YJB1803, YJB1599; cac3, YJB1581, YJB1836; cac1 cac2, YJB1804, YJB1802; cac2 cac3, YJB1865, YJB1864; cac1 cac3, YJB1862, YJB1863; sir1, YJB1940, YJB1941; sir1 cac1, YJB1962, YJB1961; sir1 cac2, YJB2000, YJB2034; sir1 cac3, YJB1945, YJB1946; sir1 cac1 cac2, YJB2044; sir1 cac2 cac3, YJB2048; sir1 cac1 cac3, YJB2007, YJB1993.

mutant with cac1- $\Delta 1$ (see Fig. 1). The cac3 ORC site mutant grew slower and formed smaller colonies than the cacl ORC site mutant, although the number of $\mathrm{Trp}^{+}$ colonies was similar in both strains (see Fig. 1). This effect of cac3 on $\mathrm{hmr} \Delta \mathrm{A}:: \mathrm{TRP} 1$ silencing is reminiscent of the mini-col ony phenotype of cac3 strains relative to cacl and cac2 strai ns in tel omeric silencing assays (Kaufman et al. 1997). The cacl cac3 mutant was derepressed to the same degree as the cacl single mutant, suggesting that cac3 mutants may retain some CAF-I function that is lost in cacl mutants. Taken together, our results indicate that loss of CAF-I function, rather than the loss of Caclp al one, causes derepression of both HML (in sirl strains) and HMR (when the ORC site is missing).

\section{Can defects in histones give rise to shmoo clusters?}

CAF-I is unlikely to be a structural component of silent chromatin, because CAF-I localizes to replication foci in mammalian cells (Krude 1995) and overexpressed epitope-tagged Caclp localizes to nuclear foci that do not colocalize with Rap1p (Enomoto et al. 1997), a structural component of the silencers. In vitro studies identified CAF-I as an activity that preferentially assembles specifically acetylated histones $\mathrm{H} 3$ and $\mathrm{H} 4$ into nucleosomes on recently replicated DNA. Yet genes encoding CAF-I subunits are not essential for yeast cell viability, indicating that al ternative chromatin assembly mechanisms must function in cac mutants (Kaufman et al. 1997). If weakened silencing at the HM loci in cacl mutants is attributable to subtle al terations in the nucleosomes assembled at these loci, we hypothesized that mutations in CAF-I and certain mutations in histones $\mathrm{H} 3$ and $\mathrm{H} 4$ should give rise to similar phenotypes. To test this hypothesis, we analyzed the $\alpha$-factor response of strains carrying mutations in either histone $\mathrm{H} 3$ or histone $\mathrm{H} 4$.

A number of mutations in lysine 16 of histone $\mathrm{H} 4$ virtual ly el iminate $\mathrm{HM}$ silencing (e.g., histones $\mathrm{H} 4 \mathrm{~K} 16 \mathrm{~A}$ and $\mathrm{H} 4 \mathrm{~K} 16 \mathrm{Q}$ ), whereas $\mathrm{H} 4 \mathrm{~K} 16 \mathrm{R}$ causes a small, but measurable reduction in mating of MATa strains (Johnson et al. 1990; M egee et al. 1990; Park and Szostak 1990). Other mutations in the amino termini of histones $\mathrm{H} 3$ and $\mathrm{H} 4$, such as deletion of the entire $\mathrm{H} 3$ amino 
terminus or mutation of $\mathrm{H} 4$ lysines 5,8 , or 12 to arginine, have little, if any, effect on silencing, when monitored by quantitative mating assays (Johnson et al . 1990; M egee et al . 1990; Park and Szostak 1990; M organ et al. 1991; Thompson et al. 1994). As expected, we found that strains carrying the histone H4 K16A and H4 K16Q mutations did not arrest at all in response to $\alpha$-factor (data not shown), and therefore, were not informative with regard to the mechanism by which HM silencing was defective. Also consistent with published data, the $\mathrm{H} 4$ K16R strain included a population of cells that did not respond to $\alpha$-factor. However, like cacl strains, strains carrying mutations in the amino terminus of histone $\mathrm{H} 4$ (K5R, K5R K8R, K5R K12R, and K16R; Megee et al. 1990), or strains carrying deletions in the histone H3 amino terminus ( $\Delta 2-20$ and $\Delta 2-29$; Morgan et al. 1991) that are competent to mate gave rise to shmoo clusters in response to $\alpha$-factor (Fig. 5). The fact that changes within the amino terminus of histones $\mathrm{H} 3$ or $\mathrm{H} 4$ are sufficient to give rise to the shmoo cluster phenotype implies that this phenotype reflects subtle defects in the structural integrity of silenced chromatin. These results also suggest that silencing defects in the histone mutant strains (which carry a wild-type allele of CAC1), are similar to the silencing defects in strains lacking CAF-I (which carry only wild-type histone alleles).

Is the budding shmoo phenotype sensitive to Sir complex protein concentration?

The stoichiometry of Sir complex proteins is critical for silencing (Ivy et al. 1986; Marshall et al. 1987), and the concentration of Sir complex proteins is likely limiting,

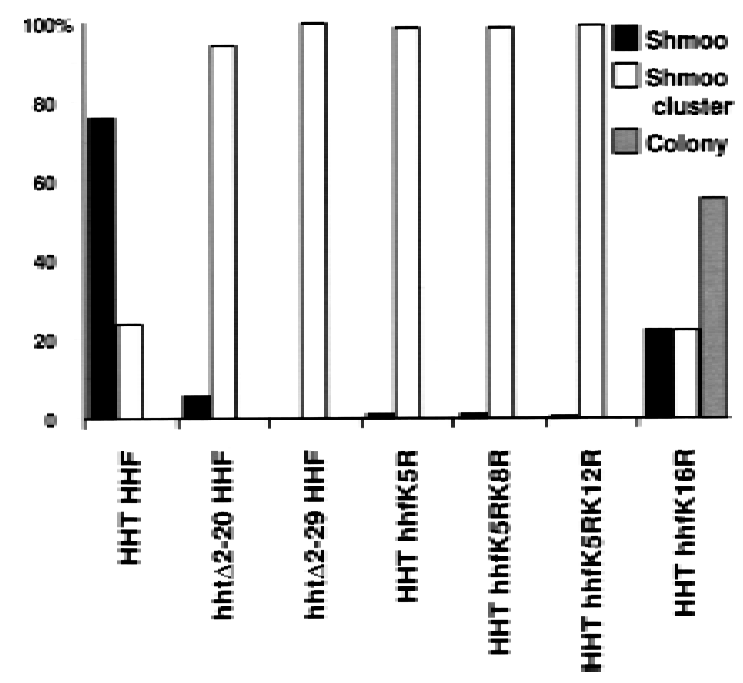

Figure 5. $\alpha$-Factor response of strains with mutations in the amino termini of histones $\mathrm{H} 3$ or $\mathrm{H} 4$. Y east cells were treated as described in Fig. 2A. $\chi^{2}$ tests indicated that HHT HHF and HHT hhfK16R were significantly different from each other and from the other histone mutants. Strains used: HHT HHF, YJB2166; hht $\Delta 2-20 \mathrm{HHF}, \mathrm{YJB} 2167$; hht $\Delta 2-29 \mathrm{HHF}$, YJB2168; HHT hhfK5R, YJB2169; HHT hhfK5R K8R, YJB2170; HHT hhfK5R K12R, YJB2171; and HHT hhfK16R, YJB2172. as under a number of conditions the telomeres and HM loci compete for Sir complex proteins (Buck and Shore 1995). Our working hypothesis is that silencing is maintained by the efficient assembly (by CAF-I) of nucleosomes and the strong association of these CAF-I-assembled nucleosomes with Sir complex proteins, which render the underlying DNA inaccessible to enzymes. This hypothesis predicts that the efficiency of silencing should be dependent on the concentration of Sir complex proteins. We tested whether providing an additional copy of each SIR gene could improve the repression of the HML locus in cacl mutants. MATa cacl strain YJB469 was transformed with a plasmid carrying either SIR1, SIR2, SIR3, or SIR4 or with the vector (YCplac33) alone, and the response to $\alpha$-factor was monitored by time-lapse microscopy. All MATa cacl cells carrying only the vector plasmid formed shmoo clusters within $18 \mathrm{hr}$ of exposure to $\alpha$-factor; no individual shmoo cells were observed. Similarly, all MATa cacl cells expressing an extra copy of SIR 1 formed shmoo clusters on $\alpha$-factor, indicating that Sirlp was not limiting in MATa cacl cells. In contrast, the presence of an extra copy of either SIR2, SIR3, or SIR4 improved the silencing and $\alpha$-factor response of MATa cacl cells; $20-30 \%$ of the cells arrested to form individual shmoos.

The ability of additional Sir $2 p$, Sir3p, or Sir $4 p$ to restore $\alpha$-factor arrest to cacl cells is consistent with the idea that cacl mutants have subtle defects in the maintenance of the heterochromatin at $\mathrm{HML}$, perhaps attributable to a limiting amount of Sir complex proteins in the complex. If this is the case, reduced concentrations of Sir complex proteins in otherwise wild-type cells should give rise to phenotypes similar to those seen in strains lacking CAF-I activity. To determine whether limiting Sir complex protein concentration can give rise to shmoo clusters, we used sir mutant strains that expressed the wild-type SIR gene from the GAL10 promoter. Cells were pregrown on raffinose, which permitted sufficient expression of the SIR genes to repress $\mathrm{HML}$. The strains were then released into glucose medium (to repress the SIR gene expression) and plated either immediately or after $2,4,6$, or $8 \mathrm{hr}$ onto $\alpha$-factor plates containing glucose. The response to $\alpha$-factor was then monitored by time-lapse microscopy. In cultures in which either SIR2 expression or SIR3 expression was repressed (by growth on glucose for $8 \mathrm{hr}$ before $\alpha$-factor exposure), shmoo clusters appeared (Fig. 6). Furthermore, the proportion of cells giving rise to shmoo clusters (and $\alpha$-factor-resistant colonies) increased with increasing time of glucose repression of either SIR2 or SIR3 before $\alpha$-factor exposure (data not shown). Thus, limiting the amount of Sir2p or Sir3p in otherwise wild-type cells is sufficient to weaken silencing and generate the budding shmoo phenotype.

\section{Discussion}

Complete HM silencing requires CAF-I

Mutations in CAF-I subunits cause derepression of the HM Ioci. Sensitive assays that detect derepression of the 


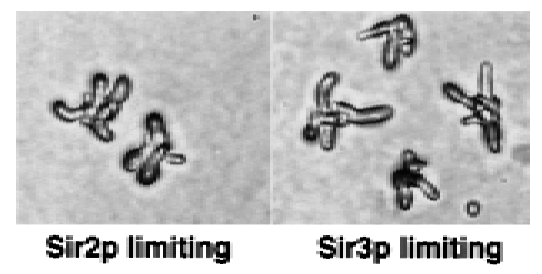

Figure 6. Limiting amounts of Sir2p or Sir3p weaken the maintenance of silencing at HML. Strains limiting for Sir2p (YJB285 [pA R 14]) or Sir3p (YJB397 [pA R 16]) were generated by pregrowth on raffinose, transfer to glucose for $8 \mathrm{hr}$, and then plating on $\alpha$-factor lacking leucine and containing glucose. Elongated shmoo clusters that arose in these cultures are shown.

HM Ioci, such as $\alpha$-factor arrest or HMR::TRP1 expression, reveal silencing defects in cac mutant strains at both HML and HMR. The unusual budding shmoo phenotype observed in MATa cacl cells grown on $\alpha$-factor plates provides a new tool for analyzing the mechanisms of silencing. Derepression of the HML $\alpha$ locus causes the budding shmoo phenotype seen in cacl cells, because we do not see shmoo clusters in a MATacacl HMLa strain.

\section{Sirlp and CAF-I contribute to different aspects} of mating silencing

Mutation of either SIR1 or CAC1 causes subtle mating defects. However, there are important differences between sirl and cacl mutant strains. cacl and sirl mutants have different relationships with the sites in the HMRE silencer. The silencing defect of sirl cells is enhanced when the Abf 1 site is deleted from HMRE (Chien et al. 1993). In contrast, the silencing defect of cacl cells is enhanced only in strains lacking the ORC site at HMRE. Most important, sirl cells exist in one of two distinct epigenetic states that can be detected by their responses to $\alpha$-factor: (1) the derepressed state that forms colonies, and (2) the repressed state that arrests as shmoos. In contrast, cacl cells are not found in two distinct states; they all appear to form shmoo clusters with similar kinetics. Moreover, sirl and cacl cells respond very differently when SIR3 is restored to sir3 cells (Fig. 3). Clearly, SIR1 is required for the re-establishment of the silent state at $\mathrm{HML}$, whereas $C A C 1$ is not required for the re-establishment process.

We propose that the budding shmoo phenotype reflects a transient defect in the maintenance, rather than the reestablishment of HML silencing. The following observations lead us to this proposal. First, the budding shmoo phenotype does not occur in cacl mutants that lack $\alpha$ information at $\mathrm{HML}$, indi cating that it is derepression of $H M L \alpha$ that gives riseto the phenotype. Second, in hmr::TRP1 strains lacking the ORC site, cacl colonies are smaller than sirl or sir4 col onies on medium lacking tryptophan. Similarly, clusters of MATacacl cells dividing on $\alpha$-factor are much smaller than MATa sir4 or MATasirl colonies. The smaller size of cacl colonies is consistent with the idea that, in cacl cells, both $\mathrm{HML}$ and HMR are partially, rather than completely, dere pressed. Third, the shmoo-bud-shmoo cycle observed in cacl cells suggests that HML derepression occurs be cause the HML locus in each cacl cell oscillates between the repressed state (because cells initially respond to $\alpha$ factor) and the derepressed state (because cells form new mating projections/buds at a time when wild-type cells have not recovered from $\alpha$-factor arrest). Fourth, this oscillation between the two states of $\mathrm{HML}$, and the loss of this oscillation in most MATa cacl sirl cells, implies that Sirlp facilitates the re-establishment of repression at the HML locus in cacl cells. Finally, alterations in either the quantity or quality of the major components of yeast heterochromatin (Sir complex proteins and histones, respectively) give rise to the budding shmoo phenotypes, suggesting that the shmoo cluster response to $\alpha$-factor reflects subtle defects in the structural integrity of the heterochromatin itself. Thus, we propose that Caclp (and CAF-I) are required for the structural integrity, or maintenance, of yeast silent chromatin.

\section{A model for silencing at HM loci}

Previously, we proposed that CAF-I is required for telomeric silencing because it promotes efficient nucleosome assembly and permits rapid association of Sir complex proteins with telomeres and telomere-adjacent regions (Enomoto et al. 1997). The study of HM silencing in cacl mutants allows us to extend this model to the maintenance of silencing at the HM loci as well. We propose that nucleosomes assembled from appropriately acetylated histones form a solid "foundation" on which a strong "wall" of silent chromatin is built (Fig. 7). The Sir complex proteins are essential "bricks" in this silencing wall. We propose that DNA and nucleosomes protected by a stable Sir protein wall remain completely inaccessible to enzymes including histone acetylases and histone deacetylases. In addition, the wall of Sir complex proteins may become unstable if the foundation of nucleosomes is weakened by the presence of histones with inappropriately acetylated amino termini (Fig. 7).

\section{Role of CAF-I in the assembly of silent chromatin}

We propose that CAF-I contributes to the association of Sir complex proteins with the heterochromatin domain in two ways. First, CAF-I ensures that replicationcoupled nucl eosome assembly occurs soon after the replication fork has passed through the heterochromatin. Second, CAF-I ensures that the nucleosomes are assembled from the appropriately acetylated histones, forming a solid foundation for Sir complex propagation.

Timing of nucleosome assembly We posit that CAF-Imediated nucleosome assembly facilitates the rapid association of Sir complex proteins whose local concentration is likely to be high immediately after replication. Because Raplp local ization and presumably Sir complex localization as well are perturbed in cac mutants (Enomoto et al. 1997), it appears that the concentration of 
Figure 7. Model for the mechanism by which CAF-I contributes to formation of stable heterochromatin. Heterochromatin is represented as a "wall" of Sir complex proteins (Sir2p, Sir3p, and Sir4p) built on a foundation of nucleosomes (circles) composed of appropriately acetylated histones. After replication, existing nucleosomes (white circles) are randomly distributed between daughter strands of DNA. (Top) CAF-I assembles newly synthesized nucleosomes (gray circles) into chromatin. Existing Sir complex proteins (white rectangles), as well as newly synthesized Sir complex proteins (gray rectangles), associate with the nucleosomes to form a wall of proteins that restrict accessibility to the DNA. If Sir complex proteins are limiting, the wall is thinner or weaker. (Middle) If derepression of the locus occurs, nucleosomes with the "ac-

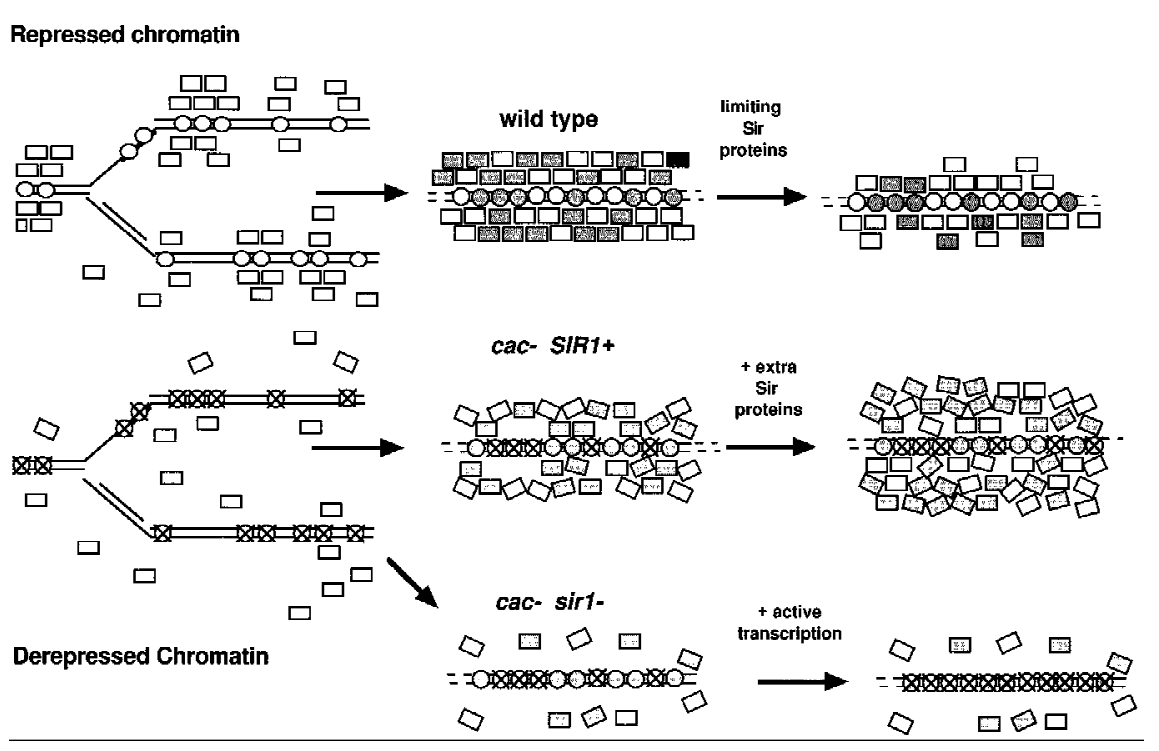
tive" acetylation patterns generated during the previous cell cycle (white circles with X) form an unstable foundation that does not associate as tightly with the Sir complex proteins. In the absence of CAF-I, these nucleosomes are recycled onto daughter strands and a fragile wall of Sir complex proteins (recruited by Sirlp) is subject to "leaking" or eventual derepression. If extra Sir complex proteins are provided, the wall can become thicker and thus, more stable. (Bottom) In cac sirl double mutants, an unstable foundation (attributable to the lack of CAF-I) and limited recruitment of Sir complex proteins (attributable to the lack of Sirlp) leads to more derepression of the locus.

heterochromatin proteins at telomeres (and presumably at the HM loci) is reduced in cells lacking CAF-I, and that these proteins are distributed more randomly throughout the nucleus. If chromatin assembly is delayed, the local Sir complex concentration near silencers may decrease as a result of diffusion of the proteins over the time required for assembly of nucleosomes. This would lead to the formation of a silencer wall with fewer bricks (Fig. 7). Because the efficiency of silencing is a function of competition between transcription activators and the silent chromatin components such as Sir3p (Renauld et al. 1993), a wall composed of fewer Sir proteins at $\mathrm{HML}$ would be less effective at restricting the accessibility of the transcriptional machinery to the $\alpha$ genes at $\mathrm{HML}$.

Assembly of nucleosomes from appropriately acetylated histones How is the repressed chromatin state inherited and how does CAF-I contribute to that inheritance? Sogo et al. (1986) demonstrated that preexisting nucleosomes segregate randomly after DN A replication. Thus, the replicated chromatin is composed of histones present in the previous cell cycle as well as newly synthesized histones. Because the acetylation pattern of histone $\mathrm{H} 4$ in silent chromatin (Braunstein et al. 1996) resembles the acetylation pattern conferred on histone $\mathrm{H} 4$ by the cytoplasmic histone acetyltransferase Hatlp (Kleff et al. 1995; Parthun et al. 1996), we propose that the acetylation pattern of histones within silent chromatin remains unaltered and old nucleosomes from the silent domain can be recycled within the silent domain after replication. The incorporation of these recycled nucleosomes (that resemble nucleosomes assembled from newly syn- thesized histones) into silent chromatin would facilitate the inheritance of the silent chromatin state (Fig. 7).

Active chromatin is characterized by a histone acetylation pattern that is different from newly synthesized or silent chromatin. Mammalian CAF-I preferentially assembles newly synthesized, cytoplasmic histones (Verreault et al. 1996). Assuming that yeast CAF-I has a simiIar activity, we propose that the role of CAF-I is to ensure that only appropriately acetylated histones are assembled into silent chromatin (Fig. 7). CAF-I may exclude histones with the "active" acetylation pattern from being recycled into silent chromatin, which is especially relevant when an HM locus has become dere pressed in the previous cell cycle.

Shmoo clusters appear when structural components of heterochromatin are altered

Our experiments with histone $\mathrm{H} 3$ and histone $\mathrm{H} 4 \mathrm{mu}$ tants support the idea that defects in the nucleosome foundation lead to defects in the maintenance of silencing. Mutations that al ter the histone amino termini give rise to budding shmoo cells, suggesting that a defect in the ability of histones $\mathrm{H} 3$ or $\mathrm{H} 4$ to be acetylated is sufficient to cause a problem with the maintenance of silencing.

Our model suggests that CAF-I ensures that Iocal Sir2p, Sir3p, and Sir $4 p$ concentrations are elevated enough to permit assembly of a strong silencer and that in the absence of CAF-I, the local concentration of Sir complex proteins decreases, because of simple diffusion of the proteins over time (Fig. 7). Our observation that an additional copy of either Sir2p, Sir3p, or Sir $4 p$ improves 
Table 1. Yeast strains used in this study

\begin{tabular}{|c|c|c|}
\hline Strain names & Genotype & Source \\
\hline \multicolumn{3}{|l|}{ S150B-2 } \\
\hline YJB276 & 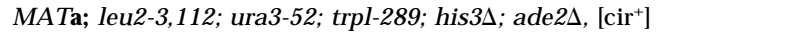 & Berman lab \\
\hline YJB277 & MAT $\alpha$; leu2-3,112; ura3-52; trp1-289; his3s; ade2 $\left[\mathrm{cir}^{+}\right]$ & Berman lab \\
\hline YJB485 & 276 cac1-1 (rlf2-1, Enomoto et al. 1997) & Berman lab \\
\hline YJB335 & 276 sir1::LEU 2 & Berman lab \\
\hline YJB744 & 276 HIS $^{+}$cac1-1 sir1::LEU 2 & this study \\
\hline YJB1289 & 277 lys2; VR-ADE2-TEL & this study \\
\hline YJB469 & $276 \operatorname{cac} 1 \Delta 1$ (=rlf2- $\Delta 1::$ LEU 2 ; Enomoto et al. 1997) & Berman lab \\
\hline YJB2057 & 276 HMLa cac1- $\Delta 1$ & this study \\
\hline YJB285 & 276 sir2::HIS3 & Berman lab \\
\hline YJB397 & 276 sir3::TRP1 & Berman lab \\
\hline \multicolumn{3}{|l|}{ W303 } \\
\hline YJB195 & MATa ura3-1, ade2-1, his3-11, leu 2-3,112, can1-100, trp1-1 & Berman lab \\
\hline YJB209 & MAT $\alpha$ ura3-1, ade2-1, his3-11, leu 2-3,112, can1-100, trp1-1 & Berman lab \\
\hline YjB959 & 195 HMR::TRP1 & D. Shore \\
\hline YJB955 & 195 hmr $\Delta$ A::TRP1 (missing ORC site) & D. Shore \\
\hline YJB1143 & 195 hmr $\Delta \mathrm{B}:: T R P 1$ (missing Abf1 (site) & D. Shore \\
\hline YJB1104 & 195 hmr $\Delta \mathrm{E}:$ :TRP1 (missing Rapl site) & D. Shore \\
\hline YJB1960 & 195 cac1- $\Delta 1$ HMR::TRP1 & this study \\
\hline YJB958 & 195 cac1- $\Delta 1$ hmr $\Delta$ A ::TRP1 & this study \\
\hline YJB1139 & 195 cac1- $\Delta 1$ hmr $\Delta$ B::TRP1 & this study \\
\hline YJB1101 & 195 cacl- $\Delta 1$ hmr $\Delta$ E::TRP1 & this study \\
\hline YJB1638 & 195 rap1-12 hmr $\Delta$ A::TRP1 & D. Shore \\
\hline YJB2006 & 195 sir1::HIS3 HMR::TRP1 & this study \\
\hline YJB2011 & 195 msil::hisG-URA3-hisG hmr $\Delta$ A::TRP1 & this study \\
\hline YJB2009 & 195 cac1- $\Delta 1$ msil::hisG-U RA3-hisG hmr $\Delta$ A::TRP1 & this study \\
\hline YJB1838 & 195 cac1- $\Delta 1$ & this study \\
\hline YJB1578 & 209 cac1- $\Delta 1$ & this study \\
\hline YJB1803 & 195 cac2::TRP1 & this study \\
\hline YJB1599 (=pky086) & 209 cac2::TRP1 & P. Kaufman \\
\hline YJB1581 & 195 msil::hisG & P. Kaufman \\
\hline YJB1836 & 209 msil::his G-URA3-hisG & this study \\
\hline YJB1804 & 195 cac1- $\Delta 1$ cac2::TRP1 & this study \\
\hline YJB1802 & 209 cac1- $\Delta 1$ cac2::TRP1 & this study \\
\hline YJB1865 & 195 cac2::TRP1 msil::hisG-U RA3-hisG & this study \\
\hline YJB1864 & 209 cac2::TRP1 msil::hisG-URA3-hisG & this study \\
\hline YJB1862 & 195 msil::hisG-U RA 3-hisG cac1- $\Delta 1$ & this study \\
\hline YJB1863 & 209 msil::hisG-URA3-hisG cac1- $\Delta 1$ & this study \\
\hline YJB1919 & 195 cac1- $\Delta 1$ cac2::TRP1 msil::his G-U RA3-hisG & this study \\
\hline YJB1918 & 209 cac1- $\Delta 1$ cac2::TRP1 msil::hisG-U RA3-hisG & this study \\
\hline YJB1940 & 195 sir1::HIS3 & this study \\
\hline YJB1941 & 209 sir1::HIS3 & this study \\
\hline YJB1962 & 195 sir1::HIS3 cac1- $\Delta 1$ & this study \\
\hline YJB1961 & 209 sir1::HIS3 cac1- $\Delta 1$ & this study \\
\hline YJB2000 & 195 sir1::HIS3 $\Delta$ cac2::TRP1 & this study \\
\hline YJB2034 & 209 sir1::HIS3 $\Delta$ cac2::TRP1 & this study \\
\hline YJB1945 & 195 sirl::HIS3 $\Delta$ msil::hisG-URA3-hisG & this study \\
\hline YJB1946 & 209 sir1::HIS3 $\Delta$ msil::hisG-U RA3-hisG & this study \\
\hline YJB2044 & 195 sir1::HIS3 $\Delta$ cac1- $\Delta 1$ cac2::TRP1 & this study \\
\hline YJB2048 & 195 sir1::HIS3 $\Delta$ cac2::TRP1 msil::hisG-U RA3-hisG & this study \\
\hline YJB2007 & 195 sir1::HIS3 $\Delta$ msil::hisG-URA3-hisG cac1- $\Delta 1$ & this study \\
\hline YJB1993 & 209 sir1::HIS3 $\Delta$ msil::hisG-URA3-hisG cac1- $\Delta 1$ & this study \\
\hline YJB2109 & 195 cac1- $\Delta 1$ sir3::TRP1 & this study \\
\hline YJB2471 & 195 sir1::HIS3 sir3::TRP1 & this study \\
\hline YJB2544 & 195 sir3::TRP1 & this study \\
\hline \multicolumn{3}{|l|}{ MX4-22A (S288C) } \\
\hline YJB2166(=M SY 552) & MATa ura3-52 lys2 201 leu2-3,112 $\Delta($ HHT1 HHF1) $\Delta($ HHT2 HHF2) & \\
\hline & pM S337[CEN ARS LEU 2 HHT1 HHF1] & M.M. Smith \\
\hline YJB2167 (M SY343) & 2166 hht1-1 ( $\Delta 2-20)$ & M.M. Smith \\
\hline YJB2168 (M SY344) & 2166 hht1-2 ( $\Delta 2-29)$ & M.M. Smith \\
\hline YJB2169 (MSY541) & 2166 hhf1-21 (KR5) & M.M. Smith \\
\hline YJB2170 (M SY 613) & 2166 hhf1-14 (KR5KR8) & M.M. Smith \\
\hline YJB2171 (MSY641) & 2166 hhf1-15 (KR5KR12) & M.M. Smith \\
\hline YJB2172 (M SY 742) & 2166 hhf1-13 (KR16) & M.M. Smith \\
\hline \multicolumn{3}{|l|}{ Miscellaneous } \\
\hline A364A & MATa adel ural gal 1 ade2 tyr1 his7 lys2 & L. Hartwell \\
\hline B364B & MAT $\alpha$ adel ural gal 1 ade 2 tyr1 his7 lys 2 & L. Hartwell \\
\hline TD1 & MAT $\alpha$ his4-38 ura3-52 trp1-289 & Berman lab \\
\hline
\end{tabular}


silencing is consistent with the idea that in strains lacking CAF-I activity, the concentration of Sir complex proteins at the silencers is suboptimal for silencing. Also consistent with this idea, decreasing the concentration of Sir $2 p$ or Sir3p in CAC1 cells results in the appearance of budding shmoos, indicating that, in otherwise wildtype cells, suboptimal Sir complex protein concentrations are sufficient to give rise to silencing defects like those seen in cacl strains.

\section{Role of CAF-I in the Sirl independent maintenance} of silencing

Our studies indicate that CAF-I and Sirlp act synergistically to silence HML in MATa cells. In SIRI cells, if HML becomes derepressed re-establishment of silencing occurs, presumably because Sirlp can attract more Sir complex proteins and can nucleate the formation of a silencer when the local concentration of Sir complex proteins decreases bel ow the threshol d for Sirlp independent maintenance. In most sirl $\Delta$ cells, repressed HM Ioci remain silent (Pillus and Rine 1989). Because this is not true in sirls cacls cells, we presume that CAF-I-assembled nucleosomes contribute to the ability of recycled and new Sir complex proteins to associate with the heterochromatin and to form a silencer wall of sufficient "thickness" (Fig. 7). In sirls cells, derepressed HM loci remain active, presumably because once expression of an HM locus occurs, histone acetylation patterns are al tered by the transcriptional machinery, and the local concentration of Sir complex proteins decreases (M aillet et al. 1996). In this case, recycled histones would not have the appropriate acetylation pattern (Fig. 7) and the local concentration of Sir complex proteins would not be sufficient to attract newly synthesized Sir complex proteins to the region. We assume that sir $1 \Delta$ cac $1 \Delta$ cells become derepressed more frequently (because of the Iack of CAF-I) and, once derepressed, silencing cannot be reestablished (because of the lack of Sirlp).

\section{Materials and methods}

Plasmids and strains

Plasmids pJR910, pJR69, pJR273, and pJR368, carrying SIR1, SIR2, SIR3, and SIR4, respectively, were provided by Jasper Rine, University of California, Berkeley. Yeast strains used in this study are listed in Table 1 . Strains were constructed by standard crosses within isogenic genetic backgrounds. SIR I was disrupted in W303 using pJR533 (Kimmerly and Rine 1987). To construct strain YJB2057, pJH132 (carrying GAL-HO) was induced to switch HML $\alpha$ to HMLa in a sir4 strain (Klar et al. 1981), allowing it to mate as a MAT $\alpha$ cell. A Leu ${ }^{+}$segregant from this cross, which was unable to switch mating type in the presence of GAL-HO expression, was selected. The strain was then cured of pJH132. pSIR3 (pSE334) includes the complete SIR3 gene in YCPlac1l1 (Gietz and Sugino 1988).

\section{Quantitative mating assay}

To assay mating of specific strains, $10^{5}$ cells were mixed with $10^{6}$ tester cells for $4.5 \mathrm{hr}$ at $30^{\circ} \mathrm{C}$ on solid complete synthetic medium (Rose et al. 1990). M ating mixtures were excised from the solid medium, resuspended in sterile water, and serial dilutions of the mixtures were plated on appropriate solid media to select for diploids or for haploid parents. Four assays were performed for each strain. The mating competence of the mutants (proportion of diploids to total cells) was expressed as a proportion of the mating competence of wild-type cells, which were al ways included in the same sets of experiments. A rank sum test (Snedecor and Cochran 1980) was performed on the ratio of diploid/total for each experiment in pairwise combination with all other strains tested in the same experiment.

\section{$\alpha$-Factor response}

Liquid assays were performed by incubating the rel evant strains in YPAD (Rose et al. 1990) containing $500 \mathrm{ng} / \mathrm{ml}$ of $\alpha$-factor (Sigma, St. Louis, MO) for $3 \mathrm{hr}$. Time lapse assays were performed on the appropriate solid YPAD medium. Five microliters of $\alpha$-factor $(200 \mu \mathrm{g} / \mathrm{ml})$ was placed on a $5 \mathrm{~mm}$ diameter region of the plate. The appropriate MAT a strains were streaked across this region. Just after streaking (time $=0$ ), areas containing well-separated cells were identified and marked by puncturing the agar surface nearby with a dissecting needle. The location and cell shape were detected and recorded with an Olympus BX-40 Photomicroscope III, equipped with a CoolCAM liquid-cooled three-chip color CCD camera (Cool Camera Co.) and captured using Image Pro Plus version 1.3 software (M edia Cybernetics). Cells were incubated at $23^{\circ} \mathrm{C}$ and then scored at different times after streaking. The $\chi^{2}$ test of goodness to fit (Snedecor and Cochran 1980) was performed by taking the distribution of wild type into three classes as the null model and testing each strain against this model. Similarly, pairs of mutant strains were tested against one another. Samples were considered significantly different at the $p<0.01$ level.

\section{Limiting Sir protein experiments}

sir2 (YJB285) and sir3 (YJB397) strains carrying either GAL-SIR2 (pAR14) or GAL-SIR3 (pAR16) (Holmes et al. 1997), respectively, were pregrown on raffinose overnight, which allowed sufficient expression of the GAL-SIR constructs to maintain HM silencing. Cultures were diluted into SDC-Leu medium containing $2 \%$ glucose for $2,4,6$, or $8 \mathrm{hr}$, to repress Sir complex protein expression, before assaying $\alpha$-factor response on solid medium containing glucose as described above.

\section{Acknowledgments}

We thank J. Broach, P. Kaufman, J. Rine, D. Shore, and M.M. Smith for providing yeast strains and plasmids. We al so thank Mark Sanders, of the University of M innesota Imaging Center, for assistance with time-lapse video microscopy, Sue Wick for use of her microscope, camera, and image collection system, and Cathy Asleson, Janna Beckerman, Kathleen Conklin, Jodi Lew, Steve Johnston, and P.T. M agee for critical reading of the manuscript. This work was supported by the $\mathrm{N}$ ational Institutes of Health (GM 38626).

The publication costs of this article were defrayed in part by payment of page charges. This article must therefore be hereby marked "advertisement" in accordance with 18 USC section 1734 solely to indicate this fact.

\section{References}

Bell, S.P., R. Kobayashi, and B. Stillman. 1993. Yeast origin recognition complex functions in transcription silencing and DN A replication. Science 262: 1844-1849. 
Brand, A.H., G. Micklem, and K. Nasmyth. 1987. A yeast silencer contains sequences that can promote autonomous plasmid replication and transcriptional activation. Cell 51: 709-719.

Braunstein, M., R.E. Sobel, C.D. Allis, B.M. Turner, and J.R. Broach. 1996. Efficient transcriptional silencing in Saccharomyces cerevisiae requires a heterochromatin histone acetylation pattern. Mol. Cell. Biol. 16: 4349-4356.

Buck, S.W. and D. Shore. 1995. Action of a RAP1 carboxy-terminal silencing domain reveals an underlying competition between HMR and telomeres in yeast. Genes \& Dev. 9: 370384.

Chien, C.-t., S. Buck, R. Sternglanz, and D. Shore. 1993. Targeting of SIR1 protein establishes transcriptional silencing at HM loci and telomeres in yeast. Cell 75: 531-555.

Enomoto, S., M.S. Longtine, and J. Berman. 1994. TEL +CEN antagonism on plasmids involves telomere repeat sequence tracts and gene products that interact with chromosomal tel omeres. Chromosoma 103: 237-250.

Enomoto, S., P.D. McCune-Zierath, M. Gerami-N ejad, and J. Berman. 1997. RLF2, a subunit of yeast chromatin assembly factor-I, is required for tel omeric chromatin function in vivo. Genes \& Dev. 11: 358-370.

Ferguson-Smith, A.C. 1996. Imprinting moves to the center. Nature Genet. 14: 119-121.

Fox, C.A. and J. Rine. 1996. Influences of the cell cycle on silencing. Curr. Opin. Cell Biol. 8: 354-357.

Fox, C.A., A.E. Ehrenhofer-Murray, S. Loo, and J. Rine. 1997. The origin recognition complex, SIR 1 , and the S phase requirement for silencing. Science 276: 1547-1551.

Gietz, R.D. and A. Sugino. 1988. N ew yeast-Escherichia coli shuttle vectors constructed with in vitro mutagenized yeast genes lacking six-base pair restriction sites. Gene 74: 527534.

Gotta, M., T. Laroche, A. Formenton, L. M aillet, H. Scherthan, and S.M. Gasser. 1996. The clustering of telomeres and colocalization with Rap1, Sir3 and Sir4 proteins in wild-type Saccharomyces cerevisiae. J. Cell Biol. 134: 1349-1363.

Gotta, M., S. Strahl-Bolsinger, H. Renauld, T. Laroche, B.K. Kennedy, M. Grunstein, and S.M. Gasser. 1997. Localization of Sir2p: The nucleolus as a compartment for silent information regulators. EMBO J. 16: 3343-3255.

Grunstein, M., A. Hecht, G. Fisher-Adams, J. Wan, R.K. Mann, S. Strahl-Bolsinger, T. Laroche, and S. Gasser. 1995. The regulation of euchromatin and heterochromatin by histones in yeast. J. Cell Sci. 19: 29-36.

Hall, J.G. 1990. Genomic imprinting: Review and relevance to human diseases. Am. J. Hum. Genet. 46: 857-873.

Hardy, C.F.J., D. Balderes, and D. Shore. 1992. Dissection of a carboxy-terminal region of the yeast regulatory protein RAP1 with effects on both transcriptional activation and silencing. Mol. Cell. Biol. 12: 1209-1217.

Hecht, A., T. Laroche, S. Strahl-Bolsinger, S.M. Gasser, and M. Grunstein. 1995. Histone $\mathrm{H} 3$ and $\mathrm{H} 4 \mathrm{~N}$-termini interact with SIR3 and SIR4 proteins: A molecular model for the formation of heterochromatin in yeast. Cell 80: 583-592.

Hecht, A., S. Strahl-Bolsinger, and M. Grunstein. 1996. Spreading of transcriptional repressor SIR3 from telomeric heterochromatin. Nature 383: 92-96.

Holmes, S.C. and J.R. Broach. 1996. Silencers are required for inheritance of the repressed state in yeast. Genes \& Dev. 10: 1021-1032.

Holmes, S.G., A.B. Rose, K. Steuerle, E. Saez, S. Sayegh, Y.M. Lee, and J.R. Broach. 1997. Hyperactivation of the silencing proteins, Sir $2 p$ and Sir3p, causes chromosome loss. Genetics 145: 605-614.
Hubbard, E.J., X.L. Yang, and M. Carlson. 1992. Relationship of the CAMP-dependent protein kinase pathway to the SNF1 protein kinase and invertase expression in Saccharomyces cerevisiae. Genetics 130: 71-80.

Ivy, J.M., A.J. Klar, and J.B. Hicks. 1986. Cloning and characterization of four SIR genes of Saccharomyces cerevisiae. Mol. Cell. Biol. 6: 688-702.

John, R.M. and M.A. Surani. 1996. Imprinted genes and regulation of gene expression by epigenetic inheritance. Curr. Opin. Cell Biol. 8: 348-353.

Johnson, L.M., P.S. Kayne, E.S. Kahn, and M. Grunstein. 1990. Genetic evidence for an interaction between SIR3 and Histone $\mathrm{H} 4$ in the repression of the silent mating loci in Saccharomyces cerevisiae. Proc. Natl. Acad. Sci. 87: 62866290.

Kaufman, P.D., R. Kobayashi, N. Kessler, and B. Stillman. 1995. The p150 and p60 subunits of chromatin assembly factor I: A molecular link between newly synthesized histones and DNA replication. Cell 81: 1105-1114.

Kaufman, P.D., R. Kobayashi, and B. Stillman. 1997. Ultraviolet radiation sensitivity and reduction of telomeric silencing in Saccharomyces cerevisiae cells lacking chromatin assembly factor-I. Genes \& Dev. 11: 345-357.

Kimmerly, W.J. and J. Rine. 1987. Replication and segregation of plasmids containing cis-acting regulatory sites of silent mating-type genes in Saccharomyces cerevisiae are controlled by the SIR genes. Mol. Cell. Biol. 7: 4225-4237.

Klar, A.J.S., J.N. Strathern, and J.B. Hicks. 1981. A positioneffect control for gene transposition: State of expression of yeast mating-type genes affects their ability to switch. Cell 25: 517-524.

Kleff, S., E.D. Andrulis, C.W. Anderson, and R. Sternglanz. 1995. Identification of a gene encoding a yeast histone $\mathrm{H} 4$ acetyltransferase. J. Biol. Chem. 270: 24674-24677.

Krude, T. 1995. Chromatin assembly factor 1 (CAF-1) colocalizes with replication foci in HeLa cell nuclei. Exp. Cell Res. 220: 304-311.

Lalande, M. 1996. Parental imprinting and human disease. Annu. Rev. Genet. 30: 173-195.

Latham, K.E. 1996. X chromosome imprinting and inactivation in the early mammalian embryo. Trends Genet. 12: 134138.

Loo, S., C.A. Fox, J. Rine, R. Kobayashi, B. Stillman, and S. Bell. 1995a. The origin recognition complex in silencing, cellcycle progression, and DNA-replication. Mol. Biol. Cell 6: 741-756.

Loo, S., P. Laurenson, M. Foss, A. Dillin, and J. Rine. 1995b. Roles of ABF1, NPL3 and YCL54 in silencing in Saccharomyces cerevisiae. Genetics 141: 889-902.

Mahoney, D.J. and J.R. Broach. 1989. The HML mating-type cassette of Saccharomyces cerevisiae is regulated by two separate but functionally equivalent silencers. Mol. Cell. Biol. 9: 4621-4630.

Mahoney, D.J., R. Marquardt, G.-J. Shei, A.B. Rose, and J.R. Broach. 1991. Mutations in the HMLE silencer of Saccharomyces cerevisiae yield metastable inheritance of transcriptional repression. Genes \& Dev. 5: 605-615.

Maillet, L., C. Boscheron, M. Gotta, S. M arcand, E. Gilson, and S.M. Gasser. 1996. Evidence for silencing compartments within the yeast nucleus: A role for telomere proximity and Sir protein concentration in silencer-mediated repression. Genes \& Dev. 10: 1796-1811.

Marshall, M., D. Mahoney, A. Rose, J.B. Hicks, and J.R. Broach. 1987. Functional domains of SIR4, a gene required for position effect regulation in Saccharomyces cerevisiae. Mol. Cell. Biol. 7: 4441-4452. 
McN ally, F.J. and J. Rine. 1991. A synthetic silencer mediates SIR-dependent functions in Saccharomyces cerevisiae. Mol. Cell. Biol. 11: 5648-5659.

Megee, P.C., B.A. Morgan, B.A. Mittman, and M.M. Smith. 1990. Genetic analysis of histone H4: Essential role of lysines subject to reversi ble acetylation. Science 247: 841-845.

Micklem, G., A. Rowley, J. Harwood, K. N asmyth, and J.F.X. Diffley. 1993. Yeast origin recognition complex is involved in DNA replication and transcriptional silencing. Nature 366: 87-89.

Miller, A.M . and K.A. N asmyth. 1984. Role of DNA replication in the repression of silent mating-type loci in yeast. Nature 312: 247-251.

Moazed, D., A. Kistler, A. Axelrod, J. Rine, and A.D. Johnson. 1997. Silent information regulator protein complexes in Saccharomyces cerevisiae: A SIR2/SIR4 complex and evidence for a regulatory domain in SIR4 that inhibits its interaction with SIR3. Proc. Natl. Acad. Sci. 94: 2186-2191.

Moretti, P., K. Freeman, L. Coodly, and D. Shore. 1994. Evidence that a complex of Sir proteins interacts with the silencer and telomere-binding protein Rapl. Genes \& Dev. 8: 2257-2269.

M organ, B.A., B.A. Mittman, and M.M. Smith. 1991. The highly conserved $\mathrm{N}$-terminal domains of histones $\mathrm{H} 3$ and $\mathrm{H} 4$ are required for normal cell cycle progression. Mol. Cell. Biol. 11: 4111-4120.

Park, E.C. and J.W. Szostak. 1990. Point mutations in the yeast histone $\mathrm{H} 4$ gene prevent silencing of the silent mating type Iocus HML. Mol. Cell. Biol. 10: 4932-4934.

Parthun, M.R., J. Widom, and D.E. Gottschling. 1996. The major cytoplasmic histone acetyltransferase in yeast: Links to chromatin replication and histone metabolism. Cell 87: 8594.

Pillus, L. and J. Rine. 1989. Epigenetic inheritance of transcriptional states in S. cerevisiae. Cell 59: 637-647.

Renauld, H., O.M. A paricio, P.D. Zierath, B.L. Billington, S.K. Chhablani, and D.E. Gottschling. 1993. Silent domains are assembled continuously from the telomere and are defined by promoter distance and strength, and SIR3 dosage. Genes \& Dev. 7: 1133-1145.

Rine, J. and I. Herskowitz. 1987. Four genes responsible for a position effect on expression from HML and HMR in Saccharomyces cerevisiae. Genetics 116: 9-22.

Rose, M.D., F. Winston, and P. Hieter. 1990. Methods in yeast genetics. Cold Spring Harbor Laboratory Press, Cold Spring Harbor, NY.

Ruggieri, R., K. Tanaka, M. N akafuku, Y. Kaziro, A. Toh-e, and K. M atsumoto. 1989. MSI 1, a negative regulator of the RASCAMP pathway in Saccharomyces cerevisiae. Proc. Natl. Acad. Sci. 86: 8778-8782.

Smith, S. and B. Stillman. 1991. Stepwise assembly of chromatin during DNA replication in vitro. EMBO J. 10: 971-980.

Snedecor, G.W. and W.G. Cochran. 1980. Statistical methods, 7th ed. The lowa State University Press, Ames, IA.

Sogo, J.M., H. Stahl, T. Koller, and R. Knippers. 1986. Structure of replicating simian virus 40 minichromosomes. The replication fork, core histone segregation and terminal structures. J. Mol. Biol. 189: 189-204.

Stillman, B. 1986. Chromatin assembly during SV40 DN A replication in vitro. Cell 45: 555-565.

Strahl-Bolsinger, S., A. Hecht, K. Luo, and M. Grunstein. 1997. SIR2 and SIR4 interactions differ in core and extended telomeric heterochromatin in yeast. Genes \& Dev. 11: 83-93.

Sussel, L. and D. Shore. 1991. Separation of transcriptional activation and silencing functions of the RAP1-encoded repressor/activator protein 1: Isolation of viable mutants affecting both silencing and telomere length. Proc. Natl. Acad. Sci. 88: 7749-7753.

Sussel, L., D. Vannier, and D. Shore. 1993. Epigenetic switching of transcriptional states: cis- and trans-acting factors affecting establishment of silencing at the HMR locus in Saccharomyces cerevisiae. Mol. Cell. Biol. 13: 3919-3928.

Thompson, J.S., X. Ling, and M. Grunstein. 1994. Histone H3 amino terminus is required for telomeric and silent mating locus repression in yeast. Nature 369: 245-247.

Triolo, T. and R. Sternglanz. 1996. Role of interactions between the origin recognition complex and SIR 1 in transcriptional silencing. Nature 381: 251-253.

Verreault, A., P.D. Kaufman, R. Kobayashi, and B. Stillman. 1996. Nucleosome assembly by a complex of CAF-1 and acetylated histones H3/H4. Cell 87: 95-104. 


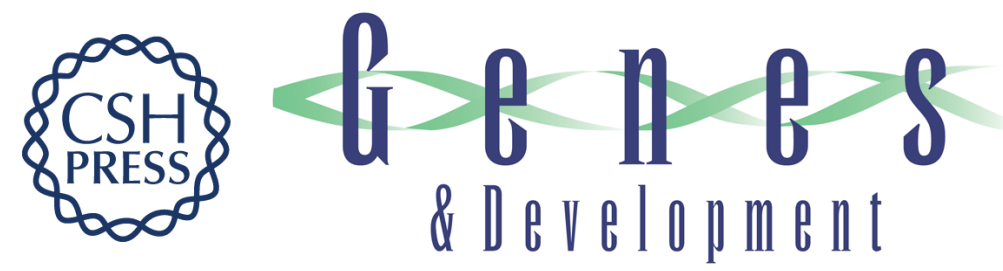

\section{Chromatin assembly factor I contributes to the maintenance, but not the re-establishment, of silencing at the yeast silent mating loci}

Shinichiro Enomoto and Judith Berman

Genes Dev. 1998, 12:

Access the most recent version at doi:10.1101/gad.12.2.219

$\begin{array}{ll}\text { References } & \text { This article cites } 60 \text { articles, } 33 \text { of which can be accessed free at: } \\ \text { http://genesdev.cshlp.org/content/12/2/219.full.html\#ref-list-1 }\end{array}$

License

Email Alerting Receive free email alerts when new articles cite this article - sign up in the box at the top Service right corner of the article or click here.

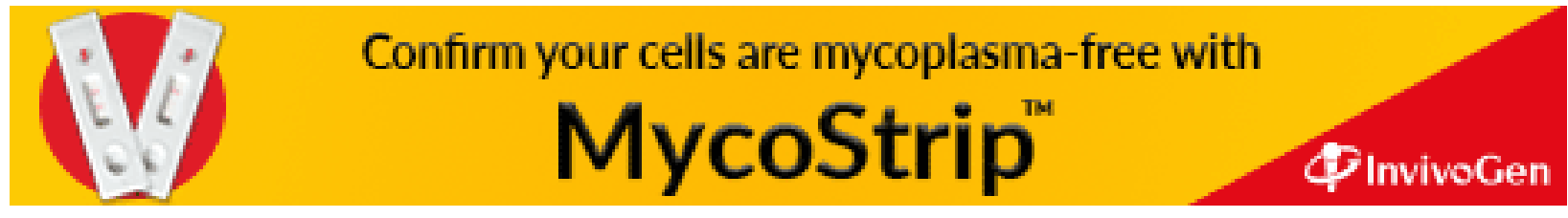

